\title{
CLINICOMICROBIOLOGICAL STUDY OF INFECTIONS DUE TO CITROBACTER SPECIES
}

Dhanya $\mathrm{A}^{1}$, Sevitha Bhat ${ }^{2}$

\section{HOW TO CITE THIS ARTICLE:}

Dhanya A, Sevitha Bhat. "Clinicomicrobiological Study of Infections due to Citrobacter Species". Journal of Evolution of Medical and Dental Sciences 2015; Vol. 4, Issue 42, May 25; Page: 7327-7331,

DOI: $10.14260 /$ jemds/2015/1063

\begin{abstract}
BACKGROUND \& OBJECTIVES: Citrobacter species have emerged as important nosocomial pathogens. The infections caused by this organism include UTI, wound infection, Neonatal sepsis, pulmonary infection, brain abscess, meningitis. The organism is recovered from a variety of clinical specimen including pus, urine, sputum. Antibiotic resistance is on rise among the Citrobacter spp. The present study was taken up to study the infections and antibiotic susceptibility pattern of Citrobacter spp. in our setup. MATERIALS AND METHODS: The study included 40 isolates of Citrobacter spp. isolated from a variety of clinical samples. Citrobacter spp. isolated were speciated using biochemical reactions. The antibiotic sensitivity testing was done by Modified Kirby-Bauer method. The risk factors associated were noted from the case records. RESULTS: Of the 40 isolates of Citrobacter species, 8 were identified as Citrobacter freundii, 18 as Citrobacter koseri, 14 as other species of Citrobacter. Of the 40 isolates, 25 were monomicrobial and the other 15 were polymicrobial. Majority of the Citrobacter isolates were from pus and Diabetes mellitus was the important risk factor. CONCLUSION: The infections are usually nosocomially acquired and are more commonly seen in patients with underlying risk factors. The incidence of these infections in hospital could be reduced by strict adherence to infection control practices and antibiotic policy.
\end{abstract}

KEYWORDS: Citrobacter spp., Risk factors, Antibiotic resistance.

INTRODUCTION: Citrobacter species are implicated in a number of infections in human beings. Three species are recognised in clinical samples: Citrobacter freundii, Citrobacter koseri (Formerly Citrobacter Diverses) and Citrobacter amalonaticus. ${ }^{1}$ Citrobacter spp. form a part of the normal intestinal flora. Citrobacter spp. are often found in human faeces and are isolated from a variety of clinical specimens. The most common sources of Citrobacter isolates are urine, sputum, and soft tissue exudates. The infections caused by this organism include UTI, Neonatal sepsis, pulmonary infection, brain abscess, meningitis. ${ }^{2}$

Antibiotic resistance is emerging among the isolates of Citrobacter spp. They are often resistant to the routinely used antibiotics, especially extended spectrum cephalosporins, due to overexpression of chromosomal beta lactamases. ${ }^{3}$ Knowledge of the antibiogram of these isolates is required for the successful therapy.

The present study is taken up to study the infections and antibiotic susceptibility pattern of Citrobacter spp. in our setup.

\section{AIMS AND OBJECTIVES:}

- To characterise the infections caused by Citrobacter spp.

- To study the occurrence of risk factors for infection with Citrobacter spp.

- To assess the antibiotic susceptibility pattern of Citrobacter spp. 


\section{ORIGINAL ARTICLE}

\section{MATERIALS AND METHODS:}

Study Design: Time bound study.

All the Citrobacter spp. isolated from various clinical samples (Blood, CSF, Pus and wound discharge, Urine, ET-tip, IV catheter) in our hospital from September 2014 onwards for a period of 6 months were included in the study.

Specimen Processing: Gram stain: Gram smear of the sample was prepared.

Wet Mount: of urine was prepared to look for the presence of pus cells and RBC's.

The samples were plated onto Blood agar, Mac Conkeys agar and Chocolate agar and incubated at $37^{\circ} \mathrm{C}$.

IDENTIFICATION: Late lactose fermenting gram negative bacilli isolated from various clinical samples were identified by conventional biochemical tests (Triple sugar iron agar test, Methyl red test, Voges Proskauer test, indole test, citrate utilization test; phenyl alanine agar test, urea hydrolysis, lysine iron agar test, arginine utilization test, ornithine utilization test, 0 nitrophenyl $\beta \mathrm{D}$ galactopyranoside test, ${ }^{1}$ and Vitek 2 system.

Antibiotic susceptibility testing was done by Modified Kirby - Bauer method and the results were interpreted according to the latest CLSI guidelines. ${ }^{4}$ The antibiotics tested included:

Amikacin, Ampicillin, Amoxycillin/Clavalanic acid, Ceftazidime, Ceftazidime/Clavulanic acid, Ceftriaxone, Cefuroxime, Cefotaxime, Chloramphenicol, Ciprofloxacin, Co-trimoxazole, Gentamycin, Imipenem, Meropenem, Ofloxacin, Ticarcillin/Clavalanic acid, Piperacillin, Piperacillin/Tazobactam, Colistin, Polymixin B, Tigecycline.

Risk Factor Analysis: Age, prior antibiotic usage, other comorbid conditions and any invasive interventions done will be recorded from the clinical case records. ${ }^{5}$

The study has received consent from the Institutional ethics committee.

Statistical analysis was done by using Chi square test.

RESULTS: Of the 40 isolates of Citrobacter species included in the study, 8 were identified as Citrobacter freundii, 18 as Citrobacter koseri, 14 as other species of Citrobacter. Of the 40 isolates, 25 were monomicrobial and the other 15 were polymicrobial, being associated with Klebsiella spp., Pseudomonas spp. Escherichia coli, Enterococcus faecalis, Acinetobacter spp., Staphylococcus aureus. Specimen wise distribution, risk factors and antibiogram of the Citrobacter isolates are shown in Tables 1, 2, 3 respectively. Of the risk factors, diabetes mellitus was statistically significant.

DISCUSSION: Citrobacter species has emerged as a nosocomial pathogen and multidrug resistance is a problem among the Citrobacter spp. In our study Citrobacter koseri was the commonest isolate, a finding consistent with previous studies. ${ }^{6}$ Some of the previous studies have reported Citrobacter freundii as the commonest isolate. ${ }^{7}$ The rate of isolation of Citrobacter koseri was $45 \%$ and the rate of isolation of Citrobacter freundi was $20 \%$.

In our study, majority of the isolates of Citrobacter spp. were from pus. Metri et al. have majority of the isolates of Citrobacter spp. being recovered from pus (48.1\%), followed by urine (24.3\%), sputum (20.3\%), body fluids (5.2\%), blood (2.1\%). 
The studies conducted by Patil et al and Shah et al have also reported maximum isolation of Citrobacter spp. from pus.8,9 In the study conducted by Mohanty, et al. majority of the isolates were from urine, followed by sputum and pus. ${ }^{10,11}$

Citrobacter infections are usually nosocomially acquired and are seen in patients with underlying risk factors: diabetes, COPD, hepatic or renal disease, instrumentation, prior antibiotic usage. Diabetes mellitus was the most important predisposing factor in this study. Other factors found to be associated with Citrobacter infections included prior antibiotic therapy and instrumentation. ${ }^{12}$

Multidrug resistance is an emerging problem among Citrobacter spp. and the fact gains more importance because of the nosocomial origin of the Citrobacter isolates. The antibiogram of the Citrobacter species revealed high levels of resistance to the commonly used antibiotics. 85\% of the strains were resistant to Ampicillin. Resistance to fluoroquinolones was in the range of $70 \%$. Among the aminoglycosides, resistance to amikacin and Gentamicin was 42.5 and $52.5 \%$ respectively. The levels of resistance to third generation cephalosporins ranged from 45-48\%, similar to previous studies. ${ }^{9,10}$ The antibiotics highly effective against the Citrobacter isolates included Carbapenems and Piperacillin Tazobactam with the resistance of $10 \%$ and $20 \%$ respectively. The worrisome fact is carbapenems are the reserve drugs and indiscriminate use of these agents would aggravate the problem further. ${ }^{13}$

The other studies conducted have also reported higher rates of resistance to the coomonly used antibiotics like ampicillin, ciprofloxacin, gentamicin, amikacin and co-trimoxazole. Previous studies have reported resistance to third generation cephalosporins and Piperacillin tazobactam to range from $39-48 \% .^{14,15}$

The antibiogram of the Citrobacter spp. in our setup has implications on the management of the infections. In our set up, cephalosporins, aminoglycosides, fluoroquinolone, or combination of these drugs are used. The higher rates of resistance observed could be due to indiscriminate use of the antibiotics.

Proper infection control practices and monitoring the trend of antibiotic resistance is a must to curb the emergence of Citrobacter spp. as a potential nosocomial pathogen.

CONCLUSION: The emergence of mutidrug resistant Citrobacter spp. as a nosocomial pathogen is alarming. The infections are usually nosocomially acquired and are more commonly seen in patients with underlying risk factors. The incidence of these infections in hospital could be reduced by strict adherence to infection control practices and antibiotic policy.

ACKNOWLEDGEMENTS: The authors are grateful to Manipal University for the facilities provided.

\section{REFERENCES:}

1. Washington Winn, Jr. Stephen Allen, William Janda, Elmer Koneman, Gary Procop, Paul Schereckenberger, Gail Woods. Koneman's Color Atlas and Text book of Diagnostic microbiology; $6^{\text {th }}$ ed; Lippincott Williams and Wilkins2008; 258-259.

2. Thapa B, Adhikari P, Mahat K, Chhetri MR, Joshi LN. Multidrug resistant nosocomial Citrobacter in a hospital in Kathmandu. Nepal Med Coll J 2009; 11: 195-9.

3. Girma Godeho, Gebre kibru and Himanot Tassew; Multidrug- resistant bacterial isolates infected wound in jimma university specialized hospital Ethiopia. Annals Of Clinical Microbiology And Antimicrobials 2013; 12 (17); 6-7. 


\section{ORIGINAL ARTICLE}

4. Clinical Laboratory Standards Institute (2010) Performance standards for antimicrobial susceptibility testing. Twenty third informational supplement Ed. In: CLSI document CLSI: Wayne, PA.

5. Ashish Khanna, Nachatal Singh, Aruna Agarwal et al. The Antibiotic Resistant Pattern In Citrobacter Species: An Emerging Nosocomial Pathogen In A Tertiary Care Hospital. Journal of clinical and Diagnostic research 2012; 6 (4) ; 642-644.

6. Metri BC, Jyothi P, Peerapur BV; Anti-microbial resistance profile of Citrobacter species in a tertiary care hospital of Southern India. Indian J Med Sci; 2011; 65 (10) ; 429-435.

7. Mohanty S, Kapil A, Dhawan B, Das BK. The bacteriological and the anti-microbial susceptibility profile of soft tissue infections from northern India. Indian J Med Sci 2004; 58 (1) : 10-15.

8. Patil MA, Lakshmi V. Antibiotic resistance among the Citrobacter species from different clinical specimens. Indian J Med Microbiol 2000; 18 (1) : 25-9.

9. Shah A, Hasan AF, Hameed A. A study on the prevalence of enterobacteriaceae in hospital acquired and community acquired inflections. Pakistan J Med Res. 2002; 41 (1) : 1-7.

10. Samonis G, Karageorgopoulous DE, Kofteridis DP, Matthaion DK, Sidiropoulou V, Maraki S, et al. Citrobacter infection in a general hospital: characteristics and outcomes. Eur J Infect Dis 2009; 28: 61.

11. Erkan Dervisolu, Zeki Yumuk, Itir Yegenaga. Citrobacter freundii peritonitis and tunnel infection in a patient on continuous ambulatory dialysis. J Med Microbiol 2008; 57: 125-127.

12. Shetty J, Kotigadde S. Antibiotic sensitivity pattern of Citrobacter isolated from various clinical specimens in a tertiary care hospital. Indian J Pathol Microbiol 2007; 50: 666-8.

13. Mohan S, Agarwal J, Srivatsava R et al. Observations on Citrobacter species from a tertiary care centre with special reference to multidrug resistnce and presence of CTX M gene. Indian J Pathol Microbiol 201451 (3) : 434-41.

14. Kurtoglu MG, Opus A, Ozdemir $M$ et al. Isolation of Citrobacter in various infectionand their antimicrobial sensitivity. Kafkas Univ vet Fak Derg 2011: 7 (Suppl A) : S 99-104.

15. Lavinge J P, Defez C, Bouziges N, Mahamat A, Sotto A. Clinical and molecular epidemiology of multidrug resistant Citrobacter species infections in French University hospital. Eur J Clin Microbiol Infect Dis 2007: 26: 439-41.

\begin{tabular}{|c|c|}
\hline Specimen & Number (percentage) \\
\hline Urine & $9(22.5)$ \\
\hline Blood & $3(7.5)$ \\
\hline Pus /exudate & $28(70)$ \\
\hline Total & $\mathbf{4 0}$ \\
\hline
\end{tabular}

Table 1 : Specimen wise distribution of Citrobacter species

\begin{tabular}{|c|c|}
\hline Risk Factor & Number (Percentage) \\
\hline Diabetes mellitus & $15(37.5 \%)$ \\
\hline Prolonged antibiotic/steroid therapy & $7(17.5 \%)$ \\
\hline Instrumentation/surgery & $6(15 \%)$ \\
\hline Malignancies & $3(7.5 \%)$ \\
\hline Immunocompromised status & $0(0 \%)$ \\
\hline Chronic pulmonary disease & $4(10 \%)$ \\
\hline
\end{tabular}




\begin{tabular}{|c|c|}
\hline Antibiotics & Number (Percentage) \\
\hline $\mathrm{A}$ & $34(85 \%)$ \\
\hline $\mathrm{Ac}$ & $29(72.5 \%)$ \\
\hline $\mathrm{Ak}$ & $17(42.5 \%)$ \\
\hline $\mathrm{Ci}$ & $18(45 \%)$ \\
\hline $\mathrm{Ce}$ & $19(47.5 \%)$ \\
\hline $\mathrm{Cu}$ & $18(45 \%)$ \\
\hline $\mathrm{Cfs}$ & $11(27.5 \%)$ \\
\hline $\mathrm{Cf}$ & $28(70 \%)$ \\
\hline $\mathrm{Co}$ & $26(65 \%)$ \\
\hline $\mathrm{G}$ & $21(52.5 \%)$ \\
\hline $\mathrm{I}$ & $4(10 \%)$ \\
\hline $\mathrm{Mr}$ & $7(17.5 \%)$ \\
\hline $\mathrm{Pc}$ & $12(30 \%)$ \\
\hline Pt & $8(20 \%)$ \\
\hline Table 3: Antibiotic Resistance \\
Pattern of Citrobacter Species \\
\hline \multicolumn{2}{|c}{} \\
\hline
\end{tabular}

*Resistance percentage.

A: Ampicillin, Ac: Amoxiclav, Ak: Amikacin, Ci: Ceftriaxone, $\mathrm{Cu}$ : Cefuroxime, Cfs: Cefaperazone sulbactam, Co: Cotrimoxazole, G: Gentamicin, I: Imipenem, Mr: Meropenem, Etp: Ertapenem, Pc: Piperacillin, Pt: Piperacillin tazobactam.

\section{AUTHORS:}

1. Dhanya A.

2. Sevitha Bhat

\section{PARTICULARS OF CONTRIBUTORS:}

1. M.Sc., Student, Department of Microbiology, Kasturba Medical College, Mangalore.

2. Associate Professor, Department of Microbiology, Kasturba Medical College, Mangalore.

FINANCIAL OR OTHER COMPETING INTERESTS: None

\section{NAME ADDRESS EMAIL ID OF THE} CORRESPONDING AUTHOR:

Dr. Sevitha Bhat,

Flat 102, Meadows, Mannagudda Road,

Ballalbagh,

Mangalore, Karnataka.

E-mail: sevitha@rediffmail.com

Date of Submission: 29/04/2015. Date of Peer Review: 04/05/2015. Date of Acceptance: 18/05/2015. Date of Publishing: 22/05/2015. 